\title{
Review Article \\ Insertion Success of the Laryngeal Tube in Emergency Airway Management
}

\author{
Michael Bernhard, ${ }^{1}$ André Gries, ${ }^{1}$ Alexandra Ramshorn-Zimmer, ${ }^{1}$ \\ Volker Wenzel, ${ }^{2}$ and Bjoern Hossfeld ${ }^{3}$ \\ ${ }^{1}$ Emergency Department, University Hospital of Leipzig, 04103 Leipzig, Germany \\ ${ }^{2}$ Department of Anaesthesiology and Critical Care Medicine, Innsbruck Medical University, 6020 Innsbruck, Austria \\ ${ }^{3}$ Department of Anaesthesiology and Intensive Care Medicine, Section Emergency Medicine, \\ Federal Armed Forces Hospital, 89081 Ulm, Germany
}

Correspondence should be addressed to Bjoern Hossfeld; bjoern.hossfeld@extern.uni-ulm.de

Received 5 May 2016; Accepted 26 June 2016

Academic Editor: Yukio Hayashi

\begin{abstract}
Copyright (C) 2016 Michael Bernhard et al. This is an open access article distributed under the Creative Commons Attribution License, which permits unrestricted use, distribution, and reproduction in any medium, provided the original work is properly cited.
\end{abstract}

\begin{abstract}
Background. Emergency airway management (AM) is a priority when resuscitating critically ill or severely injured patients. The goal of this study was to determine the success rates of LT insertion during AM. Methods. Studies that included LT first-pass insertion (FPI) and overall-pass insertion (OPI) success by emergency medical services and in-hospital providers performing AM for emergency situations as well as for scheduled surgery published until July 2014 were searched systematically in Medline. Results. Data of 36 studies $(n=1,897)$ reported a LT FPI success by physicians of $82.5 \%$ with an OPI success of $93.6 \%(p<0.001)$. A cumulative analysis of all 53 studies $(n=3,600)$ led to FPI and OPI success of $80.1 \%$ and $92.6 \%(p<0.001)$, respectively. The results of 26 studies $(n=2,159)$ comparing the LT with the laryngeal mask airway (LMA) demonstrated a FPI success of 77.0 versus $78.7 \%$ $(p=0.36)$ and an OPI success of 92.2 versus $97.7 \%(p<0.001)$. Conclusion. LT insertion failed in the first attempt in one out of five patients, with an overall failure rate in one out of 14 patients. When compared with the LT, the LMA had a cumulative $5.5 \%$ better OPI success rate.
\end{abstract}

\section{Introduction}

In critically ill or severely injured patients, efficacy of emergency airway management increased survival chances [1-3], independently of the setting in the emergency medical service, emergency departments, operating rooms, in-hospital resuscitation wards, or intensive care units $[4,5]$. While tracheal intubation is considered to be the gold standard for emergency airway management [6-8], even experienced laryngoscopists may fail to intubate resulting in significant morbidity and mortality [9-11]. Since supraglottic airway devices were described to be effective and simple to use, with a steep learning curve among providers [12-14], they were introduced into emergency airway management guidelines in the prehospital and in-hospital setting as first-line device as well as a backup strategy after failed intubation attempts $[2,15-19]$.
In 1999, the laryngeal tube was introduced to the market by VBM. In the meantime, the design has been modified several times. Currently, five versions are available, standard LT reuseable (LT), standard LT single-use (LT-D), LT with suction lumen reuseable (LTS II), LT with suction lumen single-use (LTS-D), and intubating LT, to place an endotracheal tube secondary through the lumen (iTLS D).

Although the laryngeal tube is now about 15 years in service [20], there is little data about efficacy (e.g., high success rates) in emergency airway management in the field and outside of expert centers, where more experience with this device may yield better results [13]. This may be of importance since providers need to be aware of their own and procedure-related limitations while employing the laryngeal tube and need to recognize them in a dynamic situation when a patient is threatened by hypoxia and hypercapnea [21]. More knowledge about success rates such as first-pass and 
overall-pass insertion success rates with the laryngeal tube compared with other supraglottic devices such as the laryngeal mask may also improve patient safety. While individual skills and experience may differ, it is important to know which device may score best behind the gold standard tracheal intubation.

The goal of this study was to summarize the existing evidence of first-pass and overall-pass insertion success rates of laryngeal tube insertions in the out-of-hospital and inhospital setting. Furthermore, we summarize the results of studies comparing the laryngeal tube with the laryngeal mask airway. Our hypothesis was that there would be no difference between devices being investigated.

\section{Methods}

2.1. Study Design. This study is a meta-analysis and review of the literature and does not involve the use of human subjects or medical records and thus does not require ethics approval.

2.2. Search Strategy. We searched Medline using the key words "laryngeal tube", "laryngeal tube suction", "first-pass success", "first attempt", and "overall success" as free-text terms and $\mathrm{MeSH}$ terms to identify relevant studies search strategy: [("first insertion" AND "success") OR ("insertion success") OR (“attempt” OR “attempts" AND "success") AND ("laryngeal tube" OR "laryngeal tube suction" OR "laryngeal tube suction-D" OR "LT" OR “LT-D" OR "LTS" OR ("LTSII") OR “LTS-D”)]. We also hand-searched the references and bibliographies of the included and relevant articles and reviews. Citations were screened by all authors ( $n$ $=1,234$ ), and those studies published upon 1999 meeting the predefined inclusion/exclusion criteria were then reviewed ( $n=200)$. Relevant articles, as judged by all authors, were included for full review $(n=53)$. Disagreements were resolved through a consensus process with a third author. We did not search other databases such as Embase or Cochrane Central. As the rarely available studies were performed with the different modifications mentioned above (LT, LT-D, LTS II, and LTS-D), no observations of the single types were obtained, but all types were summarized as "LT."

2.3. Inclusion and Exclusion Criteria. We considered studies in which emergency medical service personnel and inhospital and prehospital physicians, regardless of speciality background and level of training, performed airway management in a given setting (e.g., emergency medical services, emergency department, intensive care unit, airway management during scheduled surgery, and in-hospital resuscitation in wards) using the laryngeal tube. We excluded paediatric patients. Articles published in English and German were included. All case reports, case reviews, systematic reviews, letters to the editor, and animal as well as cadaver or mannequin studies were excluded.

2.4. Outcome Measures. The primary outcome measures were the first-pass and overall-pass insertion success rates of laryngeal tube insertion. Secondary outcome measures were first-pass and overall-pass insertion success rates of laryngeal mask airway (as another often used supraglottic airway device) in studies comparing laryngeal tube and laryngeal mask airway. The criterion for "successful insertion" in the included studies was adequacy of ventilation observing the presence of end-tidal carbon dioxide waveforms, chest movement, and oxygen saturation.

2.5. Statistical Analysis. The statistical analysis was performed with the statistical software package $\mathrm{R}$ (version 2.15.1). The results of first-pass and overall-pass insertion success rates of the included studies were summarized and reported in detail. Manual calculations of unadjusted effects estimates (odds ratio, OR) were performed, and the odd ratios were pooled. 95\% confidence intervals (CI) for each study and over all studies were calculated. If the success rate was $100 \%$, it was assumed that the lower confidence interval (CI) was reached and that the next attempt would fail. In those cases, the CI was marked in the results tables. We used a fixed effects model. Group comparisons of frequencies were performed using the $\mathrm{Chi}^{2}$ test. For all randomized controlled trials, the odds ratio was calculated and presented with confidence intervals in a forest plot.

\section{Results}

This search identified 1,234 citations, of which 1034 were excluded (Figure 1). We reviewed the full text of 200 studies, of which 53 studies met inclusion criteria.

3.1. First-Pass and Overall Success of Laryngeal Tube Insertion. Physicians employed the laryngeal tube during scheduled anaesthesia in 36 studies [22-56] with a total of 1,897 patients: the first-pass insertion success rate of these providers was $82.5 \%(1,452 / 1,760,95 \%$ CI: $80.7 \%-84.3 \%)$, and the overallpass insertion success rate was 93.6\% $(1,594 / 1,703)$ (95\% CI: 92.4\%-94.8\%, $p<0.001$ ) (Table 1). Paramedics, paramedic students, and BLS nurses employed the laryngeal tube in an in-hospital setting in 4 studies [57-60] including 151 patients. In this group, the first-pass insertion success rate was 53.2\% (25/47, 95\% CI: 38.9\%-67.5\%) and the overall-pass insertion success rate was $87.4 \%$ (132/151) (95\% CI: $82.1 \%-$ 92.7\%, $p<0.001$ ) (Table 2). Physicians, paramedics, first responders, and nurses employed the laryngeal tube outside the hospital in 13 studies [61-73] with 1,552 patients reporting the first-pass and/or overall-pass insertion success rates of laryngeal tube insertion to be $78.1 \%(1,212 / 1,552,95 \% \mathrm{CI}$ : $76.0 \%-80.2 \%)$ and the overall-pass insertion success rate was $91.8 \%(1,272 / 1,385)$ (95\% CI: $90.4 \%-93.3 \%, p<0.001)$ (Table 3). In the cumulative analysis with all 53 studies [2273 ] including 3,600 patients, the first-pass insertion success rate of the laryngeal tube was $80.1 \%(2,689 / 3,359)$ and the overall-pass insertion success rate was $92.6 \%(2,938 / 3,239)$ $(p<0.001)$.

3.2. Laryngeal Tube versus Laryngeal Mask Airway. In 26 studies including 2,159 patients comparing the laryngeal tube with the laryngeal mask airway in the operating room 


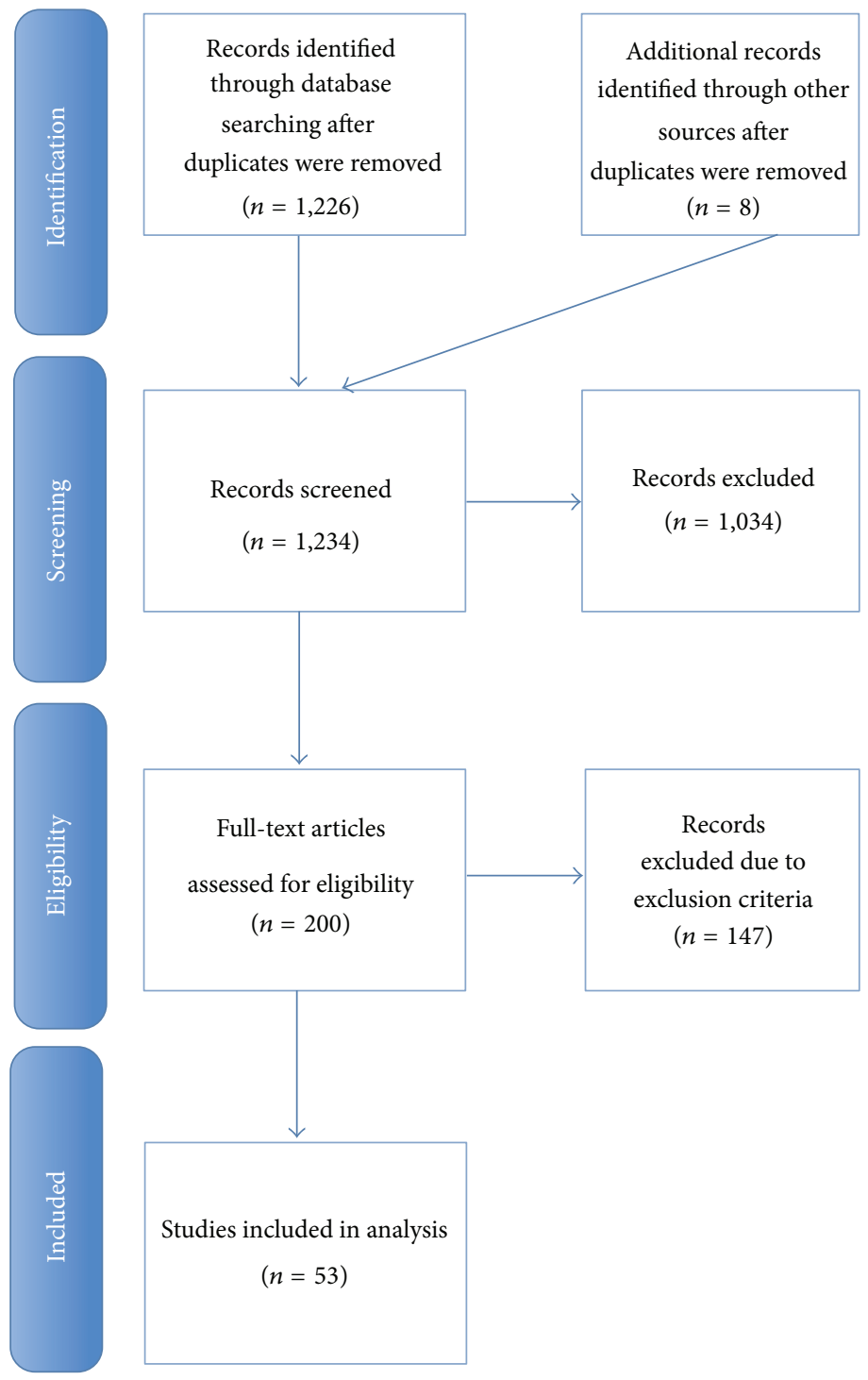

Figure 1: Flow diagram for selection of trials.

(Table 4), the first-pass insertion success rates for the laryngeal tube versus the laryngeal mask airway were $77.0 \%$ $(770 / 1,000)$ versus $78.7 \%(783 / 995)(p=0.36)$, and the overall-pass insertion success rate was $92.2 \%(970 / 1,052)$ versus $97.7(1,023 / 1,047)(p<0.001)$ (Table 4$)$. The pooled OR across all studies was 1.11 (95\% CI: $0.88-1.39$ ) for the firstpass insertion failure, indicating comparable success rates of both devices (Figure 2). The pooled OR across all studies was 2.86 (95\% CI: 1.74-4.70) for overall-pass insertion failure, indicating lower failure rate for laryngeal mask airway when compared to laryngeal tube (Figure 3).

\section{Discussion}

This study included 53 studies from 17 different countries with a pooled sample size of 3,600 patients, which is the largest summarized data set assessing laryngeal tube insertion success rates at the current time. Overall-pass insertion success rate employing the laryngeal tube was $92.6 \%$, with the laryngeal mask insertion being significantly better at $97.7 \%$.

Our results were contrary to some findings in the literature from smaller meta-analysis, which found an overall success rate of the laryngeal tube insertions $(n=150)$ of $96.5 \%$ and of the laryngeal mask airway $(n=3,829)$ of $87.4 \%$ [74]. The different overall-pass insertion success rates of laryngeal tube insertion in comparison to laryngeal mask insertion may have the following reasons: first, anaesthetists are well trained in laryngeal mask airway usage in the operating room providing anaesthesia and airway management on a daily basis [14]; emergency airway management is then just an extrapolation of daily routine with this device. For the laryngeal tube, this remains a dilemma since this supraglottic airway device is usually not being routinely employed in the operating room at all [75], which subsequently may explain the low laryngeal tube first-pass insertion success rate $(77.7 \%)$ and overall-pass insertion success rate $(92.2 \%)$ in the 


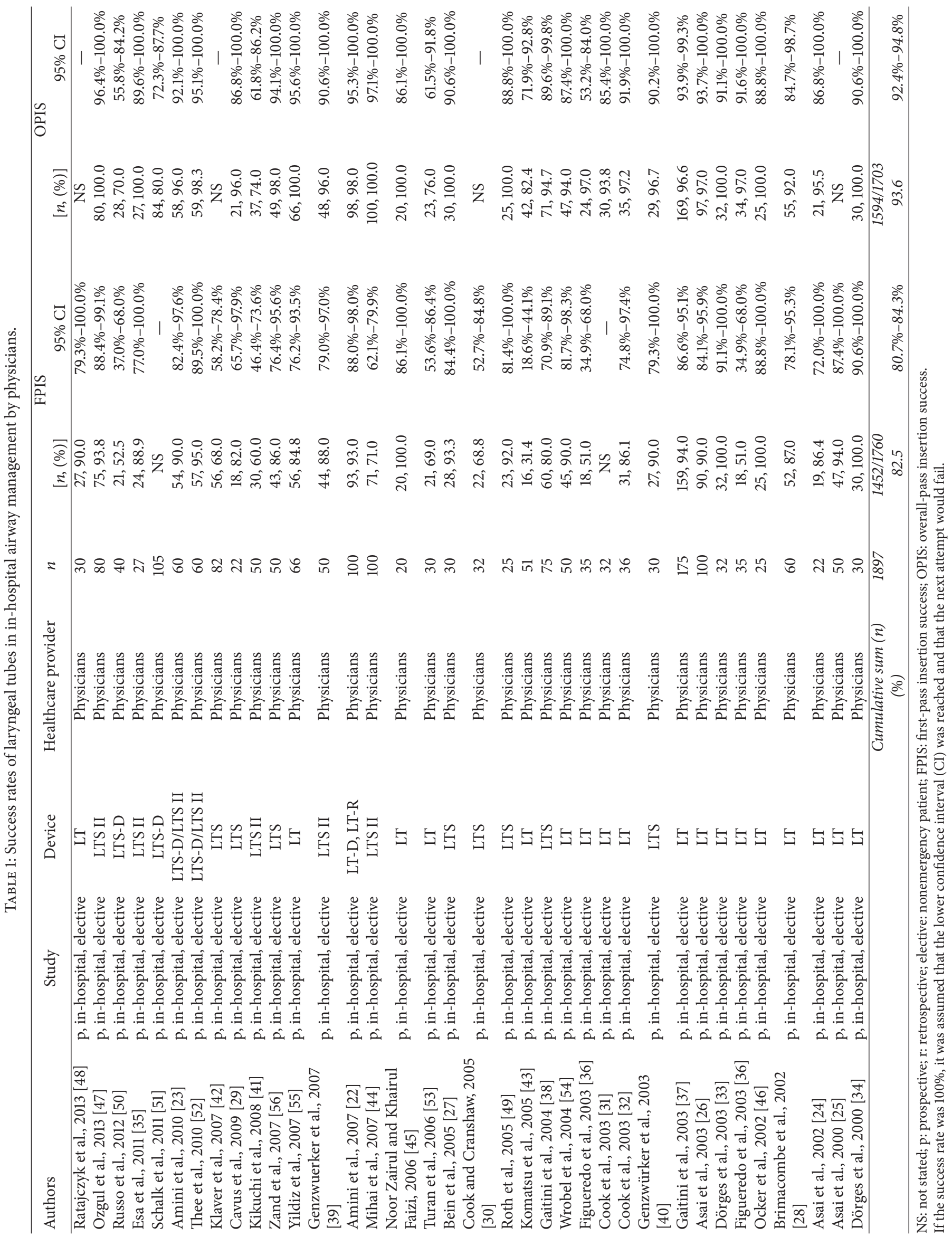




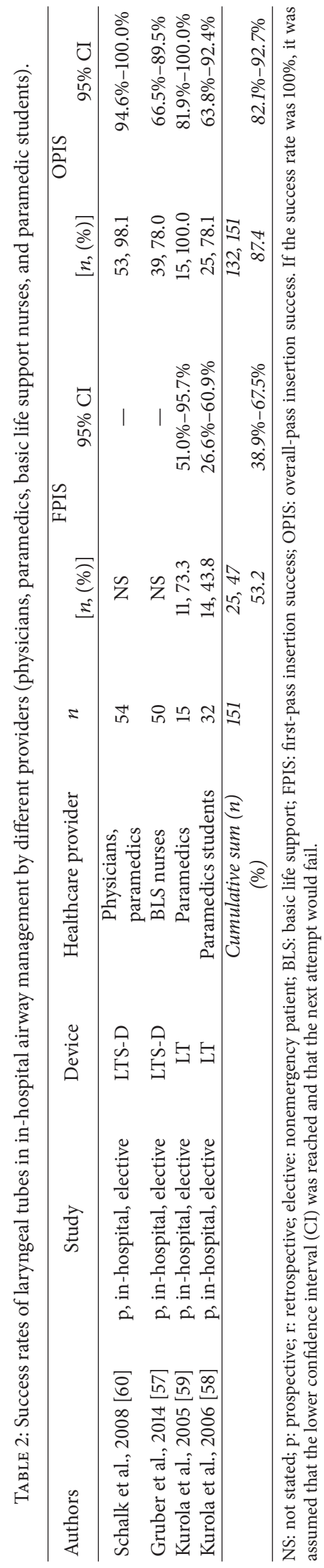




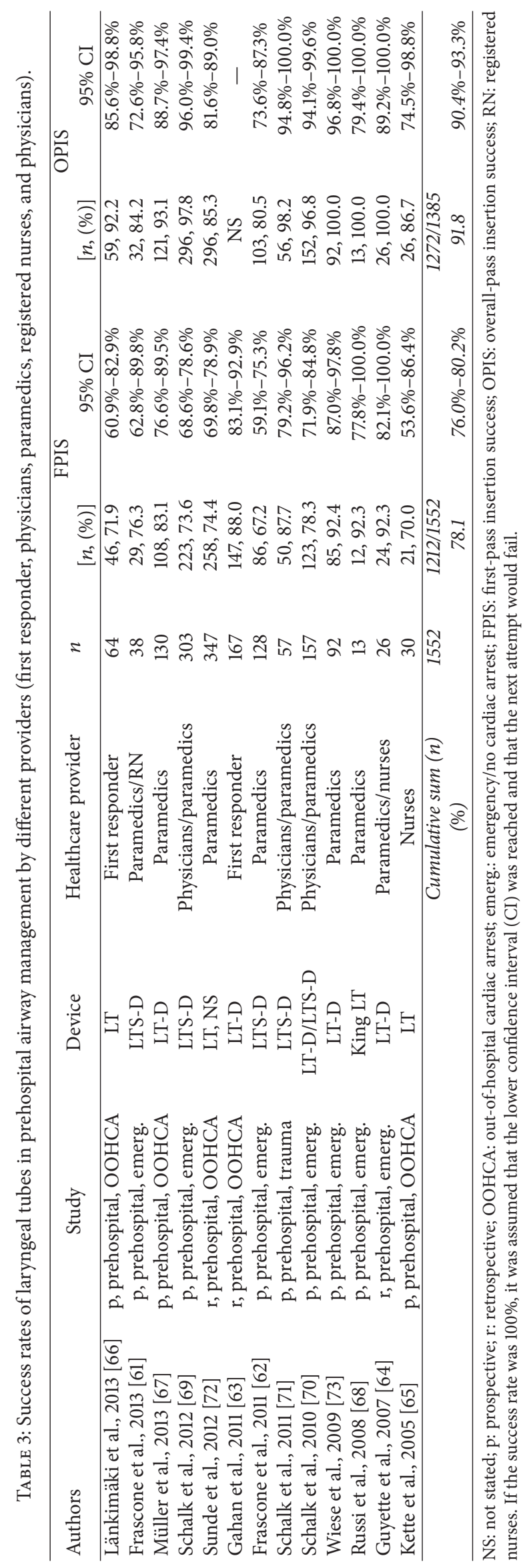




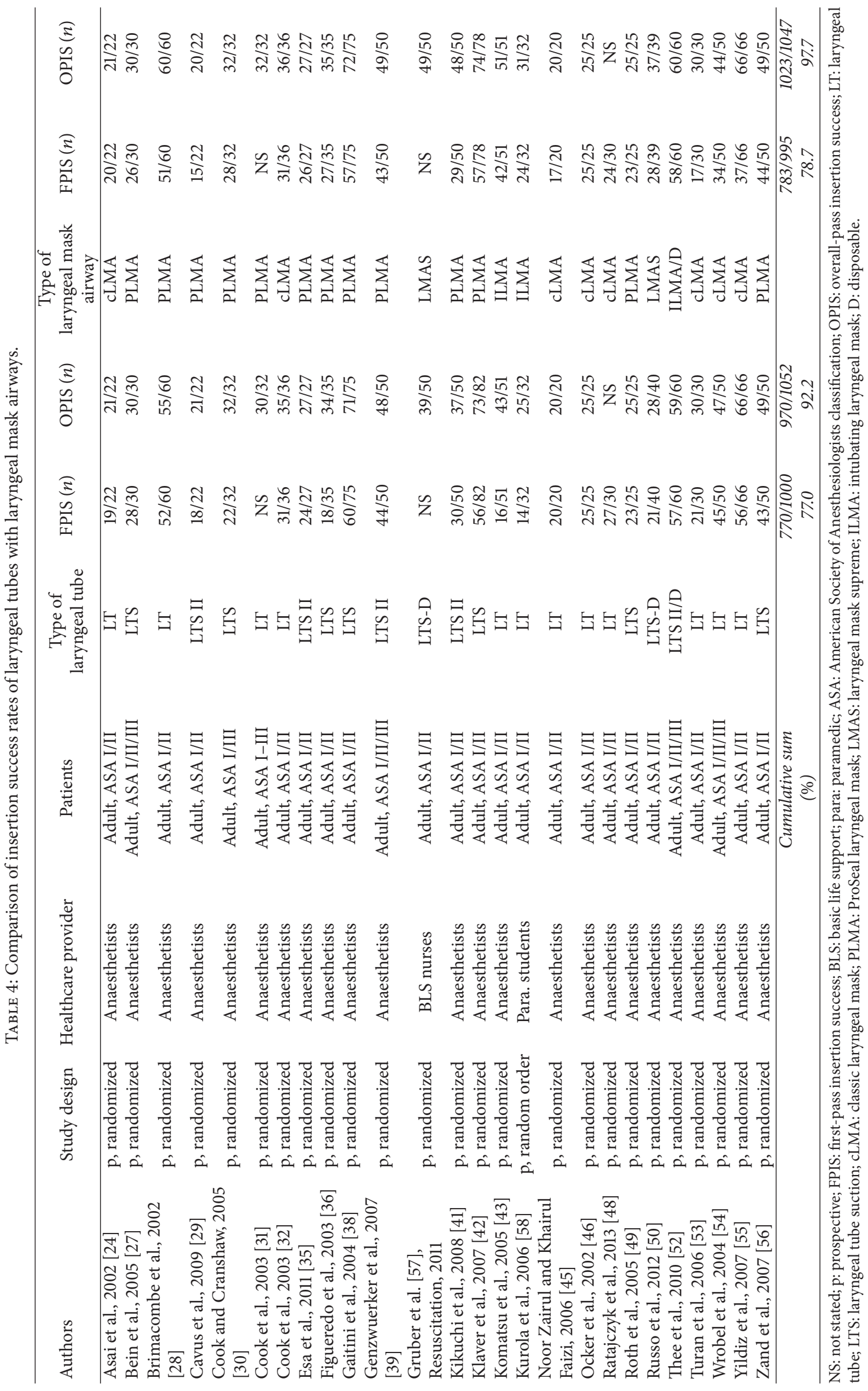




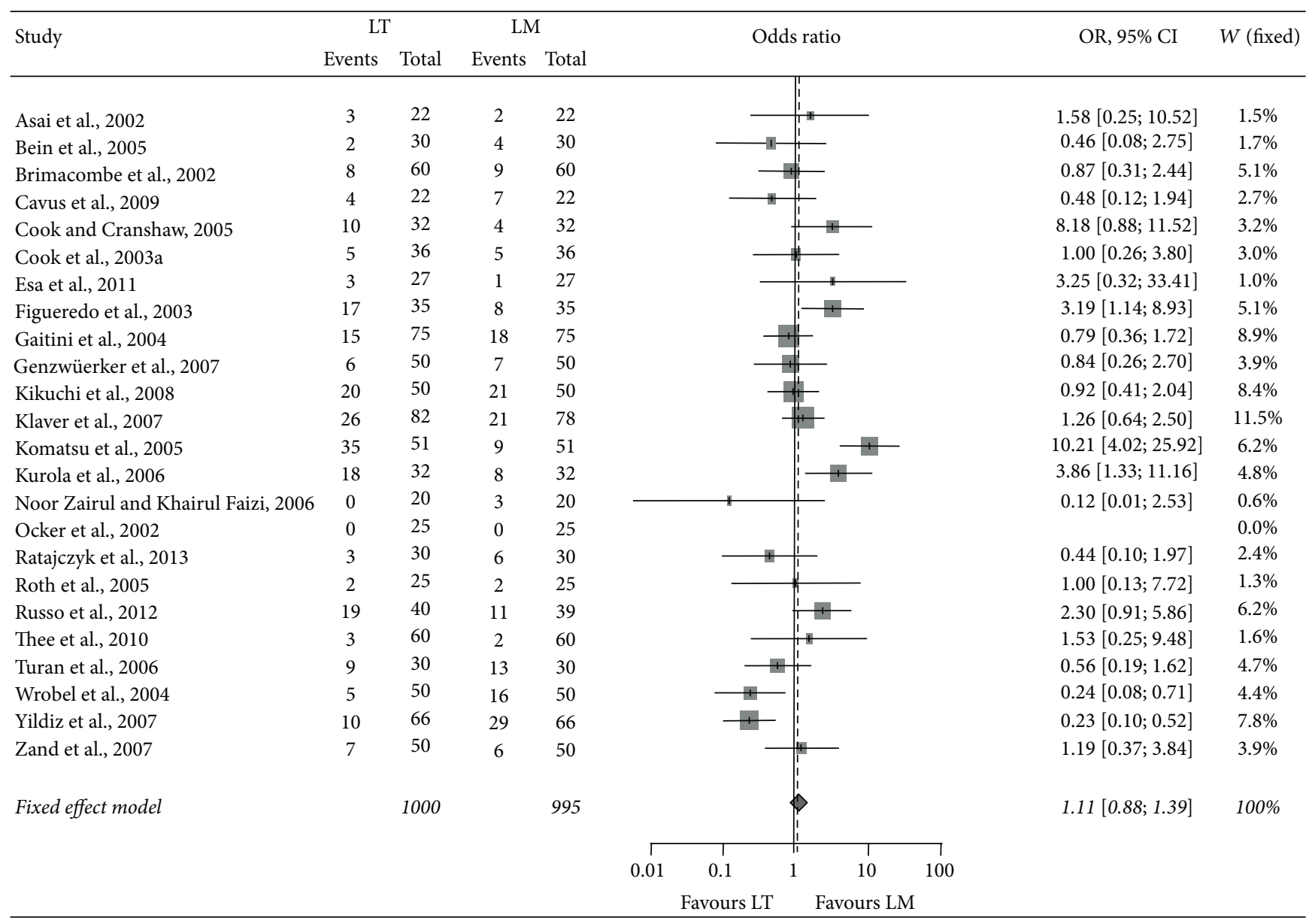

FIGURE 2: Forest plot of first-pass insertion failure (LT laryngeal tube, LM laryngeal mask).

prehospital setting. Second, if a device is not being employed routinely in the operating room, anticipated success rates in an emergency airway management situation simply have to be worse compared to the daily routine device as a difficult situation has to be managed with an unacquainted device. Third, significant problems of laryngeal tube insertion have been reported, including incorrect positioning in prehospital and in-hospital settings, which may contribute to the phenomenon of inadvertent complications $[21,76]$. A prospective study reported a complication rate of $52 \%$ in 189 patients being managed with the laryngeal tube in the prehospital setting $[76,77]$ : laryngeal tube-associated problems related to excessive cuff pressure, tongue swelling (39\%), hypoxic cardiac arrest (2\%), massive stomach distension with ventilation difficulty (11\%), and bleeding from soft tissue of the upper airway $(2 \%)[76,77]$.

A range of the previously mentioned complications were reported in the underlying studies. However, the reporting style of adverse events in those studies was unstructured and maybe incomplete. Therefore, those results have to be interpreted with caution, and a robust conclusion may not be drawn from those elective in-hospital studies.

Taken together, the laryngeal tube may not be as simple as anticipated, and lack of its daily usage in airway management including emergency cases may hamper success especially when hypoxic and hypercarbic patients need it the most [21].

The successful insertion of a supraglottic airway is important; however, this may not reflect successful ventilation with the given device during emergency conditions in all cases. Carlson et al. [78] described in a human unembalmed cadaver model that the required axial dislodgment force for a combitube required in this study is twice as much as for the endotracheal tube; and the laryngeal tube and the laryngeal mask airway dislodgment forces were similar to those of the endotracheal tube. Thereby, using secondgeneration supraglottic airway devices may optimize the seal and reduce the possibility of accidental dislodgement [76]. The current guidelines of the European Resuscitation Council [2] report rates of successful ventilation during cardiopulmonary resuscitation of $71-90 \%$ for the laryngeal mask airway in comparison to the combitube with 79-98\% and no reported percentages for the laryngeal tube. However, cardiac arrest is only one of the prehospital emergencies requiring emergency airway management; other acute settings (e.g., trauma, respiratory insufficiency) need emergency airway management as well. The included studies in this review were not able to answer the question of which supraglottic airway 


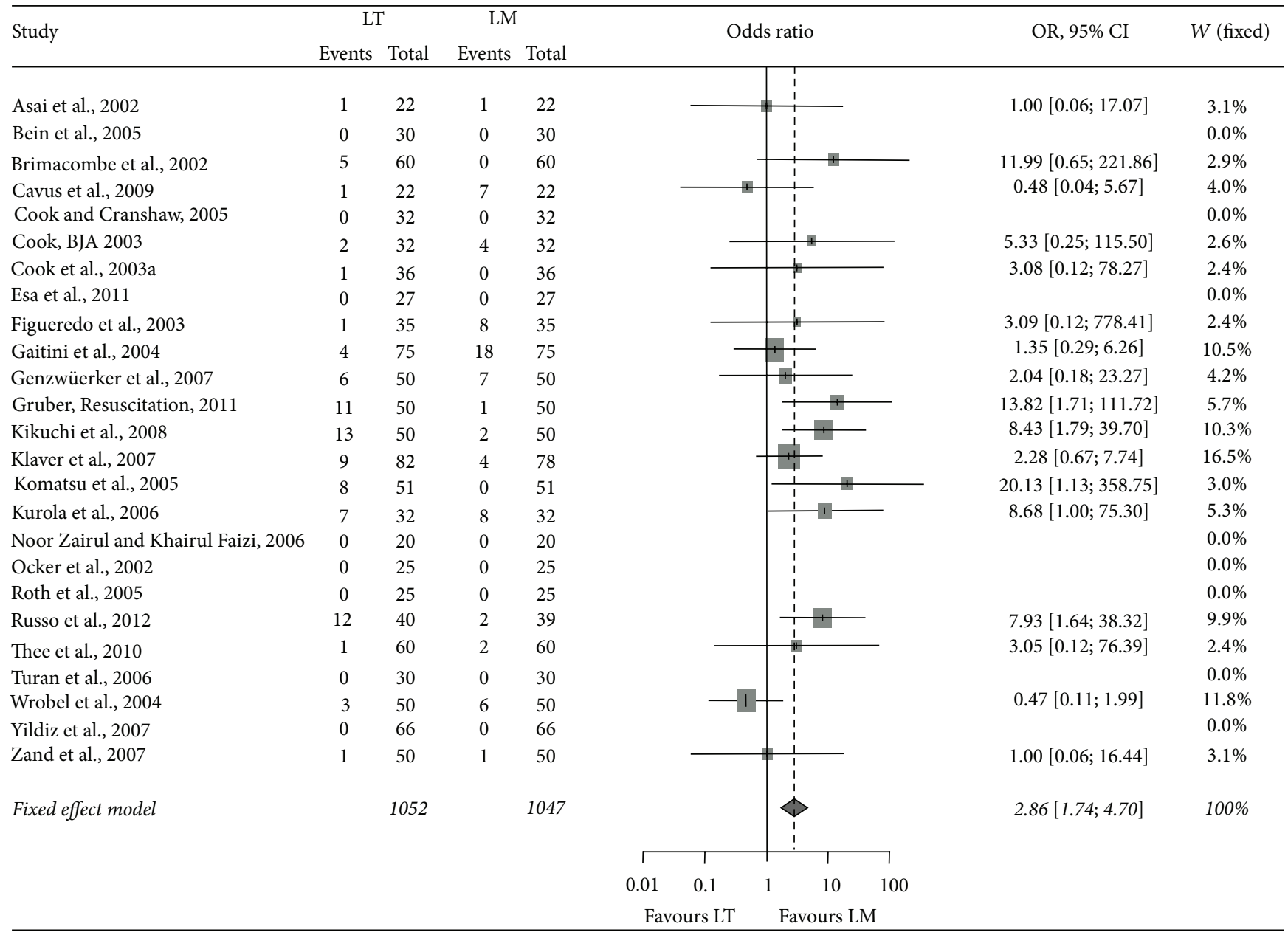

FIGURE 3: Forest plot of overall-insertion failure (LT laryngeal tube, LM laryngeal mask).

is superior to another in means of successful ventilation in emergency circumstances.

A meta-analysis and systematic review [79] assessing the survival rates of patients suffering from out-of-hospital cardiac arrest being managed with tracheal intubation versus supraglottic airway devices versus basic airway management suggested decreases in survival rates for out-of-hospital cardiac arrest victims treated by the EMS with advanced airway interventions. Unfortunately, this and other similar studies may fall prey to their design; namely, advanced airway management may simply trail ongoing resuscitation efforts. As such, a patient regaining spontaneous circulation quickly may simply not need tracheal intubation, while a patient undergoing prolonged resuscitation efforts with a slim survival chance is earmarked with advanced airway management. In this case, advanced airway management would simply be a surrogate parameter for bad outcome, but not the problem per se.

\section{Limitations}

This study has several limitations. First, the review pools existing evidence and is thus dependent on quality of reported data. Reviews of randomized controlled trials provide the strongest evidence, which only was the case in the studies comparing the laryngeal tube with the laryngeal mask airway, but not in studies investigating the laryngeal tube alone. Moreover, typical for advanced airway studies, the success rates are very high, and for the distributions these proportions may be much skewed towards the high end. Therefore, as the success proportions approach hundred percent, the variance of the study is squeezed towards zero, and, therefore, the study with the high success proportion may receive a disproportionately large weight when the inverse variance method such as fixed effects model is used. So, the pooled odds ratios of this might overestimate the effect [80]. Further, we excluded small case series and letters to the editor, which is a strength of our analysis; also, we excluded mannequin studies as this setting cannot be extrapolated directly to emergency airway management [81]. Also, the majority of data was extracted from studies with anaesthetists who are experienced in maintaining the airway, thus featuring a possible positive bias for success rates of the chosen airway device. In contrast, results from mixed providers including physicians and mostly paramedics performing laryngeal tube insertion revealed lower laryngeal tube insertion success 
rates, which further decreased when paramedics during training only inserted laryngeal tubes in the operating room, thus illustrating a learning curve. The different experience of the practitioners must be discussed; namely, some providers may have been much more skilled in using the laryngeal mask airway than the laryngeal tube and several of the comparative studies are thus a comparison of skill levels and not of devices per se. Dividing the comparative studies of the laryngeal tube and the laryngeal mask airway according to the performer level demonstrated that anaesthetists have a higher firstpass and overall-pass insertion success rate for both devices in comparison to nonanaesthetists and that first-pass and overall-pass insertion success rates of nonanaesthetists for the laryngeal tube are inferior to the laryngeal mask airway (Table 2). These results suggest that there is a device and also a provider dependent influence on success rates. This analysis, however, is limited by the small number of patients in the studies of laryngeal tube insertion by nonanaesthetists $(n=82)$. Similar to a historic discussion about the combitube, airway device-related complications may be significantly more related to the training with airway devices than to the airway devices themselves [82]. Accordingly, it is possible that the full potential of the laryngeal tube has not been detected yet as teaching with it may remain insufficient and infrequent.

\section{Conclusions}

Laryngeal tube (including its newer modifications) insertion failed in the first attempt in one out of five patients, with an overall failure rate in one out of 14 patients. When compared with the laryngeal tube, the laryngeal mask airway had a cumulative $5.5 \%$ better overall-pass insertion success rate.

\section{Competing Interests}

The authors declare that they have no competing interests in regard to topics being discussed in this paper.

\section{Funding}

This project was funded solely by departmental resources.

\section{References}

[1] P. Berlac, P. K. Hyldmo, P. Kongstad et al., "Pre-hospital airway management: guidelines from a task force from the Scandinavian Society for Anaesthesiology and Intensive Care Medicine," Acta Anaesthesiologica Scandinavica, vol. 52, no. 7, pp. 897-907, 2008.

[2] C. D. Deakin, J. P. Nolan, J. Soar et al., "European Resuscitation Council Guidelines for Resuscitation 2010 Section 4. Adult advanced life support," Resuscitation, vol. 81, no. 10, pp. 13051352, 2010.

[3] P. Paal, H. Herff, T. Mitterlechner et al., "Anaesthesia in prehospital emergencies and in the emergency room," Resuscitation, vol. 81, no. 2, pp. 148-154, 2010.

[4] T. M. Cook, N. Woodall, C. Frerk, and Fourth National Audit Project, "Major complications of airway management in the UK: results of the Fourth National Audit Project of the Royal
College of Anaesthetists and the Difficult Airway Society. Part 1: anaesthesia," British Journal of Anaesthesia, vol. 106, no. 5, pp. 617-631, 2011.

[5] T. M. Cook, N. Woodall, J. Harper, and J. Benger, "Major complications of airway management in the UK: results of the Fourth National Audit Project of the Royal College of Anaesthetists and the Difficult Airway Society-part 2: intensive care and emergency departments," British Journal of Anaesthesia, vol. 106, no. 5, pp. 632-642, 2011.

[6] R. Komatsu, Y. Kasuya, H. Yogo et al., "Learning curves for bag-and-mask ventilation and orotracheal intubation: an application of the cumulative sum method," Anesthesiology, vol. 112, no. 6, pp. 1525-1531, 2010.

[7] C. Konrad, G. Schüpfer, M. Wietlisbach, and H. Gerber, "Learning manual skills in anesthesiology: is there a recommended number of cases for anesthetic procedures?" Anesthesia and Analgesia, vol. 86, no. 3, pp. 635-639, 1998.

[8] M. Bernhard, S. Mohr, M. A. Weigand, E. Martin, and A. Walther, "Developing the skill of endotracheal intubation: implication for emergency medicine," Acta Anaesthesiologica Scandinavica, vol. 56, no. 2, pp. 164-171, 2012.

[9] A. Timmermann, S. G. Russo, C. Eich et al., "The out-ofhospital esophageal and endobronchial intubations performed by emergency physicians," Anesthesia and Analgesia, vol. 104, no. 3, pp. 619-623, 2007.

[10] A. Von Goedecke, H. Herff, P. Paal, V. Dörges, and V. Wenzel, "Field airway management disasters," Anesthesia \& Analgesia, vol. 104, no. 3, pp. 481-483, 2007.

[11] A. Gries, W. Zink, M. Bernhard, M. Messelken, and T. Schlechtriemen, "Realistic assessment of the physican-staffed emergency services in Germany," Anaesthesist, vol. 55, no. 10, pp. 1080-1086, 2006.

[12] A. Timmermann, "Supraglottic airways in difficult airway management: successes, failures, use and misuse," Anaesthesia, vol. 66, no. 2, pp. 45-56, 2011.

[13] D. G. Ostermayer and M. Gausche-Hill, "Supraglottic airways: the history and current state of prehospital airway adjuncts," Prehospital Emergency Care, vol. 18, no. 1, pp. 106-115, 2014.

[14] S. Mohr, M. A. Weigand, S. Hofer et al., "Developing the skill of laryngeal mask insertion: prospective single center study," Anaesthesist, vol. 62, no. 6, pp. 447-452, 2013.

[15] J. L. Apfelbaum, C. A. Hagberg, R. A. Caplan et al., "Practice guidelines for management of the difficult airway: an updated report by the American Society of Anesthesiologists Task Force on Management of the Difficult Airway," Anesthesiology, vol. 118, no. 2, pp. 251-270, 2013.

[16] T. Heidegger, H. J. Gerig, and J. J. Henderson, "Strategies and algorithms for management of the difficult airway," Best Practice and Research: Clinical Anaesthesiology, vol. 19, no. 4, pp. 661674, 2005.

[17] J. J. Henderson, M. T. Popat, I. P. Lotto, and A. C. Pearce, "Difficult airway society guidelines for management of the unanticipated difficult intubation," Anaesthesia, vol. 59, no. 7, pp. 675-694, 2004.

[18] H. Herff, V. Wenzel, and D. Lockey, "Prehospital intubation: the right tools in the right hands at the right time," Anesthesia and Analgesia, vol. 109, no. 2, pp. 303-305, 2009.

[19] R. W. Neumar, C. W. Otto, M. S. Link et al., "Part 8: adult advanced cardiovascular life support: 2010 American Heart Association Guidelines for Cardiopulmonary Resuscitation and Emergency Cardiovascular Care," Circulation, vol. 122, no. 3, pp. S729-S767, 2010. 
[20] F. Agro, R. Cataldo, A. Alfano, and B. Galli, "A new prototype for airway management in an emergency: the laryngeal tube," Resuscitation, vol. 41, no. 3, pp. 284-286, 1999.

[21] M. Bernhard, W. Beres, A. Timmermann et al., "Prehospital airway management using the laryngeal tube. An emergency department point of view," Anaesthesist, vol. 63, no. 7, pp. 589596, 2014.

[22] A. Amini, F. Zand, and S. E. Sadeghi, "A comparison of the disposable vs the reusable laryngeal tube in paralysed adult patients," Anaesthesia, vol. 62, no. 11, pp. 1167-1170, 2007.

[23] A. Amini, F. Zand, and M. Maghbooli, "Disposable versus reusable laryngeal tube suction for ventilation in patients undergoing laparoscopic cholecystectomy," Revista Brasileira de Anestesiologia, vol. 60, no. 1, pp. 32-41, 2010.

[24] T. Asai, A. Kawashima, I. Hidaka, and S. Kawachi, "The laryngeal tube compared with the laryngeal mask: insertion, gas leak pressure and gastric insufflation," British Journal of Anaesthesia, vol. 89, no. 5, pp. 729-732, 2002.

[25] T. Asai, K. Murao, and K. Shingu, "Efficacy of the laryngeal tube during intermittent positive-pressure ventilation," Anaesthesia, vol. 55, no. 11, pp. 1099-1102, 2000.

[26] T. Asai, K. Shingu, and T. Cook, "Use of the laryngeal tube in 100 patients," Acta Anaesthesiologica Scandinavica, vol. 47, no. 7, pp. 828-832, 2003.

[27] B. Bein, S. Carstensen, M. Gleim et al., "A comparison of the proseal laryngeal mask airway, the laryngeal tube $S$ and the oesophageal-tracheal combitube during routine surgical procedures," European Journal of Anaesthesiology (EJA), vol. 5, pp. 341-346, 2005.

[28] J. Brimacombe, C. Keller, and L. Brimacombe, "A comparison of the laryngeal mask airway ProSeal ${ }^{6}$ and the laryngeal tube airway in paralyzed anesthetized adult patients undergoing pressure-controlled ventilation," Anesthesia and Analgesia, vol. 95, no. 3, pp. 770-776, 2002.

[29] E. Cavus, W. Deitmer, H. Francksen et al., "Laryngeal tube S II, ProSeal laryngeal mask, and EasyTube during elective surgery: a randomized controlled comparison with the endotracheal tube in nontrained professionals," European Journal of Anaesthesiology, vol. 26, no. 9, pp. 730-735, 2009.

[30] T. M. Cook and J. Cranshaw, "Randomized crossover comparison of ProSeal ${ }^{\circledR}$ Laryngeal Mask Airway with Laryngeal Tube Sonda ${ }^{\circledR}$ during anaesthesia with controlled ventilation," British Journal of Anaesthesia, vol. 95, no. 2, pp. 261-266, 2005.

[31] T. M. Cook, C. McKinstry, R. Hardy, and S. Twigg, "Randomized crossover comparison of the ProSeal ${ }^{\mathrm{TM}}$ laryngeal mask airway with the Laryngeal Tube ${ }^{\circledR}$ during anaesthesia with controlled ventilation," British Journal of Anaesthesia, vol. 91, no. 5, pp. 678-683, 2003.

[32] T. M. Cook, B. McCormick, and T. Asai, "Randomized comparison of laryngeal tube with classic laryngeal mask airway for anaesthesia with controlled ventilation," British Journal of Anaesthesia, vol. 91, no. 3, pp. 373-378, 2003.

[33] V. Dörges, H. Ocker, V. Wenzel, M. Steinfath, and K. Gerlach, "The laryngeal tube S: a modified simple airway device," Anesthesia and Analgesia, vol. 96, no. 2, pp. 618-621, 2003.

[34] V. Dörges, H. Ocker, V. Wenzel, and P. Schmucker, "The laryngeal tube: a new simple airway device," Anesthesia and Analgesia, vol. 90, no. 5, pp. 1220-1222, 2000.

[35] K. Esa, I. Azarinah, M. Muhammad, M. A. Helmi, and M. Z. Jaafar, "A comparison between laryngeal tube suction II airway and Proseal laryngeal mask airway in laparoscopic sugery," Medical Journal of Malaysia, vol. 66, pp. 182-186, 2011.
[36] E. Figueredo, M. Martínez, and T. Pintanel, "A comparison of the ProSeal ${ }^{\mathrm{TM}}$ laryngeal mask and the Laryngeal Tube ${ }^{\circledR}$ in spontaneously breathing anesthetized patients," Anesthesia and Analgesia, vol. 96, no. 2, pp. 600-605, 2003.

[37] L. A. Gaitini, S. J. Vaida, M. Somri et al., "An evaluation of the laryngeal tube during general anesthesia using mechanical ventilation," Anesthesia \& Analgesia, vol. 96, no. 6, pp. 17501755, 2003.

[38] L. A. Gaitini, S. J. Vaida, M. Somri, B. Yanovski, B. Ben-David, and C. A. Hagberg, "A randomized controlled trial comparing the Proseal laryngeal mask airway with the laryngeal tube suction in mechanically ventilated patients," Anesthesiology, vol. 101, no. 2, pp. 316-320, 2004.

[39] H. V. Genzwuerker, S. Altmayer, J. Hinkelbein, C. Gernoth, T. Viergutz, and H. Ocker, "Prospective randomized comparison of the new laryngeal tube suction LTS II and the LMA-ProSeal for elective surgical interventions," Acta Anaesthesiologica Scandinavica, vol. 51, no. 10, pp. 1373-1377, 2007.

[40] H. Genzwürker, T. Finteis, J. Hinkelbein, and K. Ellinger, "First clinical experiences with the new LTS. A laryngeal tube with an oesophageal drain," Anaesthesist, vol. 52, no. 8, pp. 697-702, 2003.

[41] T. Kikuchi, Y. Kamiya, T. Ohtsuka, T. Miki, and T. Goto, "Randomized prospective study comparing the laryngeal tube suction II with the proseal laryngeal mask airway in anesthetized and paralyzed patients," Anesthesiology, vol. 109, no. 1, pp. 54-60, 2008.

[42] N. S. Klaver, K. Kuizenga, A. Ballast, and V. Fidler, "A comparison of the clinical use of the Laryngeal Tube $S^{\mathrm{TM}}$ and the ProSeal ${ }^{\circledR}$ Laryngeal Mask Airway by first-month anaesthesia residents in anaesthetised patients," Anaesthesia, vol. 62, no. 7, pp. 723-727, 2007.

[43] R. Komatsu, O. Nagata, K. Kamata, K. Yamagata, D. I. Sessler, and M. Ozaki, "Comparison of the intubating laryngeal mask airway and laryngeal tube placement during manual in-line stabilisation of the neck," Anaesthesia, vol. 60, no. 2, pp. 113-117, 2005.

[44] R. Mihai, G. Knottenbelt, and T. M. Cook, "Evaluation of the revised laryngeal tube suction: the laryngeal tube suction II in 100 patients," British Journal of Anaesthesia, vol. 99, no. 5, pp. 734-739, 2007.

[45] M. Noor Zairul and A. Khairul Faizi, "Comparison of the VBM laryngeal tube and laryngeal mask airway for ventilation during manual in-line neck stabilisation," Singapore Medical Journal, vol. 47, no. 10, pp. 892-896, 2006.

[46] H. Ocker, V. Wenzel, P. Schmucker, M. Steinfath, and V. Dörges, "A comparison of the laryngeal tube with the laryngeal mask airway during routine surgical procedures," Anesthesia and Analgesia, vol. 95, no. 4, pp. 1094-1097, 2002.

[47] U. Ozgul, Z. Begec, K. Karahan et al., "Comparison of propofol and ketamine-propofol mixture (Ketofol) on laryngeal tube-suction II conditions and hemodynamics: a randomized, prospective, double-blind trial," Current Therapeutic Research, Clinical and Experimental, vol. 75, pp. 39-43, 2013.

[48] P. Ratajczyk, B. MaŁachowska, E. Gaszyńska, and T. Gaszyński, "A randomised comparison between Cobra PLA and classic laryngeal mask airway and laryngeal tube during mechanical ventilation for general anaesthesia," Anaesthesiology Intensive Therapy, vol. 45, no. 1, pp. 20-24, 2013.

[49] H. Roth, H. V. Genzwuerker, A. Rothhaas, T. Finteis, and J. Schmeck, "The ProSeal laryngeal mask airway and the laryngeal 
tube suction for ventilation in gynaecological patients undergoing laparoscopic surgery," European Journal of Anaesthesiology, vol. 22, no. 2, pp. 117-122, 2005.

[50] S. G. Russo, S. Cremer, T. Galli et al., "Randomized comparison of the i-gel ${ }^{\mathrm{TM}}$, the LMA Supreme ${ }^{\mathrm{TM}}$, and the Laryngeal Tube Suction-D using clinical and fibreoptic assessments in elective patients," BMC Anesthesiology, vol. 12, article 18, 2012.

[51] R. Schalk, S. Engel, D. Meininger et al., "Disposable laryngeal tube suction: standard insertion technique versus two modified insertion techniques for patients with a simulated difficult airway," Resuscitation, vol. 82, no. 2, pp. 199-202, 2011.

[52] C. Thee, G. Serocki, V. Doerges et al., "Laryngeal tube S II, laryngeal tube $S$ disposable, Fastrach laryngeal mask and Fastrach laryngeal mask disposable during elective surgery: a randomized controlled comparison between reusable and disposable supraglottic airway devices," European Journal of Anaesthesiology, vol. 27, no. 5, pp. 468-472, 2010.

[53] A. Turan, G. Kaya, O. Koyuncu, B. Karamanlioglu, and Z. Pamukçu, "Comparison of the laryngeal mask $\left(\mathrm{LMA}^{6}\right)$ and laryngeal tube $\left(\mathrm{LT}^{5}\right)$ with the new perilaryngeal airway $\left(\right.$ CobraPLA $\left.^{5}\right)$ in short surgical procedures," European Journal of Anaesthesiology, vol. 23, no. 3, pp. 234-238, 2006.

[54] M. Wrobel, U. Grundmann, W. Wilhelm, S. Wagner, and R. Larsen, "Laryngeal tube versus laryngeal mask airway in anaesthetised non-paralysed patients. A comparison of handling and postoperative morbidity," Anaesthesist, vol. 53, no. 8, pp. 702708, 2004.

[55] T. S. Yildiz, M. Solak, and K. Toker, "Comparison of laryngeal tube with laryngeal mask airway in anesthetized and paralysed patients," European Journal of Anaesthesiology, vol. 24, pp. 620625, 2007.

[56] F. Zand, A. Amini, S. E. Sadeghi, M. Gureishi, and A. Chohedri, "A comparison of the laryngeal tube- $S^{6}$ and Proseal ${ }^{6}$ laryngeal mask during outpatient surgical procedures," European Journal of Anaesthesiology, vol. 24, no. 10, pp. 847-851, 2007.

[57] E. Gruber, R. Oberhammer, K. Balkenhol et al., "Basic life support trained nurses ventilate more efficiently with laryngeal mask supreme than with facemask or laryngeal tube suctiondisposable-a prospective, randomized clinical trial," Resuscitation, vol. 85, no. 4, pp. 499-502, 2014.

[58] J. Kurola, P. Pere, L. Niemi-Murola et al., "Comparison of airway management with the intubating laryngeal mask, laryngeal tube and CobraPLA by paramedical students in anaesthetized patients," Acta Anaesthesiologica Scandinavica, vol. 50, no. 1, pp. 40-44, 2006.

[59] J. O. Kurola, M. J. Turunen, J.-P. Laakso, J. T. Gorski, H. J. Paakkonen, and T. O. Silfvast, "A comparison of the laryngeal tube and bag-valve mask ventilation by emergency medical technicians: a feasibility study in anesthetized patients," Anesthesia \& Analgesia, vol. 101, no. 5, pp. 1477-1481, 2005.

[60] R. Schalk, B. Scheller, O. P. Habler, J. Meier, D. Meininger, and C. Byhahn, "Disposable laryngeal tube suction-a randomized comparison of two insertion techniques performed by novice users in anaesthetised patients," Resuscitation, vol. 76, no. 3, pp. 364-368, 2008.

[61] R. J. Frascone, S. S. Wewerka, A. M. Burnett, K. R. Griffith, and J. G. Salzman, "Supraglottic airway device use as a primary airway during rapid sequence intubation," Air Medical Journal, vol. 32, no. 2, pp. 93-97, 2013.

[62] R. J. Frascone, C. Russi, C. Lick et al., "Comparison of prehospital insertion success rates and time to insertion between standard endotracheal intubation and a supraglottic airway," Resuscitation, vol. 82, no. 12, pp. 1529-1536, 2011.

[63] K. Gahan, J. R. Studnek, and S. Vandeventer, "King LT-D use by urban basic life support first responders as the primary airway device for out-of-hospital cardiac arrest," Resuscitation, vol. 82, no. 12, pp. 1525-1528, 2011.

[64] F. X. Guyette, H. Wang, and J. S. Cole, "King airway use by air medical providers," Prehospital Emergency Care, vol. 11, no. 4, pp. 473-476, 2007.

[65] F. Kette, I. Reffo, G. Giordani et al., "The use of laryngeal tube by nurses in out-of-hospital emergencies: preliminary experience," Resuscitation, vol. 66, no. 1, pp. 21-25, 2005.

[66] S. Länkimäki, S. Alahuhta, and J. Kurola, "Feasibility of a laryngeal tube for airway management during cardiac arrest by first responders," Resuscitation, vol. 84, no. 4, pp. 446-449, 2013.

[67] J.-U. Müller, T. Semmel, R. Stepan et al., "The use of the laryngeal tube disposable by paramedics during out-of-hospital cardiac arrest: a prospectively observational study (2008-2012)," Emergency Medicine Journal, vol. 30, no. 12, pp. 1012-1016, 2013.

[68] C. S. Russi, M. J. Hartley, and C. T. Buresh, "A pilot study of the King LT supralaryngeal airway use in a rural Iowa EMS system," International Journal of Emergency Medicine, vol. 1, no. 2, pp. 135-138, 2008.

[69] R. Schalk, T. Auhuber, O. Haller et al., "Implementation of the laryngeal tube for prehospital airway management. Training of 1,069 emergency physicians and paramedics," Anaesthesist, vol. 61, no. 1, pp. 35-40, 2012.

[70] R. Schalk, C. Byhahn, F. Fausel et al., "Out-of-hospital airway management by paramedics and emergency physicians using laryngeal tubes," Resuscitation, vol. 81, no. 3, pp. 323-326, 2010.

[71] R. Schalk, D. Meininger, M. Ruesseler et al., "Emergency airway management in trauma patients using laryngeal tube suction," Prehospital Emergency Care, vol. 15, no. 3, pp. 347-350, 2011.

[72] G. A. Sunde, G. Brattebø, T. Ødegården, D. F. Kjernlie, E. Rødne, and J.-K. Heltne, "Laryngeal tube use in out-of-hospital cardiac arrest by paramedics in Norway," Scandinavian Journal of Trauma, Resuscitation and Emergency Medicine, vol. 20, article 84, 2012.

[73] C. H. R. Wiese, T. Semmel, J. U. Müller, J. Bahr, H. Ocker, and B. M. Graf, "The use of the laryngeal tube disposable (LT-D) by paramedics during out-of-hospital resuscitation-an observational study concerning ERC guidelines 2005," Resuscitation, vol. 80, no. 2, pp. 194-198, 2009.

[74] M. W. Hubble, D. A. Wilfong, L. H. Brown, A. Hertelendy, and R. W. Benner, "A meta-analysis of prehospital airway control techniques-part ii: alternative airway devices and cricothyrotomy success rates," Prehospital Emergency Care, vol. 14, no. 4, pp. 515-530, 2010.

[75] M. R. Rai and M. T. Popat, "Evaluation of airway equipment: man or manikin?” Anaesthesia, vol. 66, no. 1, pp. 1-3, 2011.

[76] R. Schalk, F. H. Seeger, H. Mutlak et al., "Complications associated with the prehospital use of laryngeal tubes-a systematic analysis of risk factors and strategies for prevention," Resuscitation, vol. 85, no. 11, pp. 1629-1632, 2014.

[77] P. Paal and A. Timmermann, "The beauty and the beast-a tale of the laryngeal tube and related potentially life threatening operational faults," Resuscitation, vol. 85, no. 12, pp. A1-A2, 2014.

[78] J. N. Carlson, J. Mayrose, and H. E. Wang, "How much force is required to dislodge an alternate airway?" Prehospital Emergency Care, vol. 14, no. 1, pp. 31-35, 2010. 
[79] P. F. Fouche, P. M. Simpson, J. Bendall, R. E. Thomas, D. C. Cone, and S. A. R. Doi, "Airways in out-of-hospital cardiac arrest: systematic review and meta-analysis," Prehospital Emergency Care, vol. 18, no. 2, pp. 244-256, 2014.

[80] J. J. Barendregt, S. A. Doi, Y. Y. Lee, R. E. Norman, and T. Vos, "Meta-analysis of prevalence," Journal of Epidemiology and Community Health, vol. 67, no. 11, pp. 974-978, 2013.

[81] C. D. Deakin, D. Murphy, M. Couzins, and S. Mason, "Does an advanced life support course give non-anaesthetists adequate skills to manage an airway?" Resuscitation, vol. 81, no. 5, pp. 539543, 2010.

[82] P. E. Pepe, B. S. Zachariah, and N. C. Chandra, "Invasive airway techniques in resuscitation," Annals of Emergency Medicine, vol. 22, no. 2, pp. 393-403, 1993. 


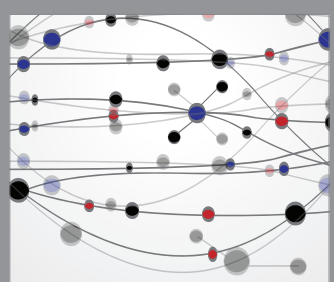

The Scientific World Journal
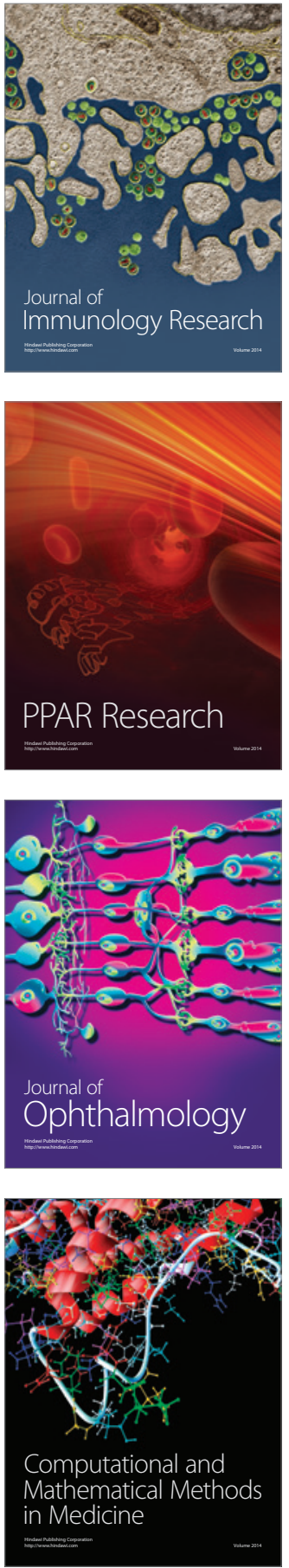

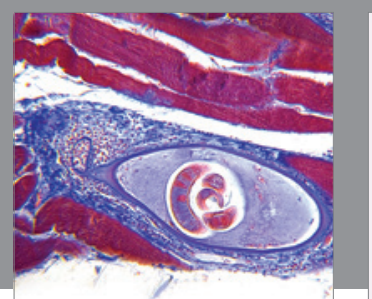

Gastroenterology Research and Practice

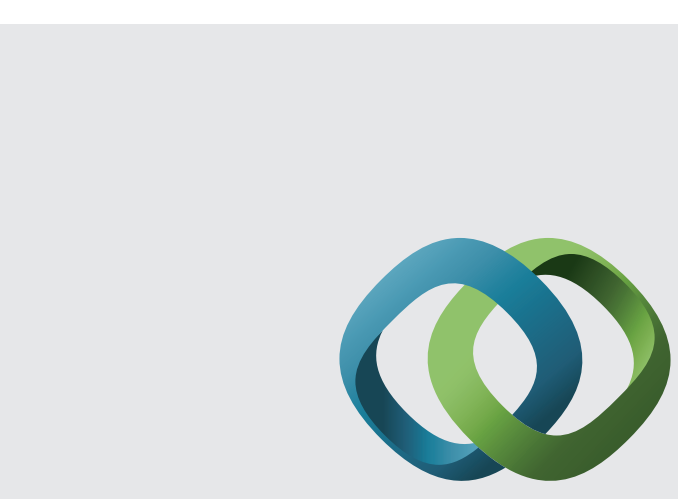

\section{Hindawi}

Submit your manuscripts at

http://www.hindawi.com
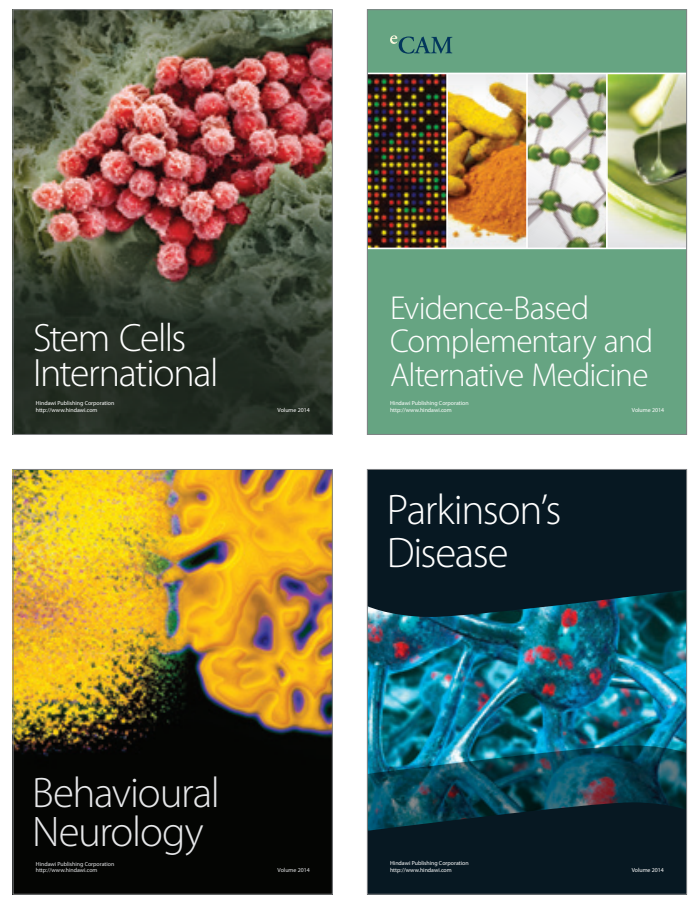
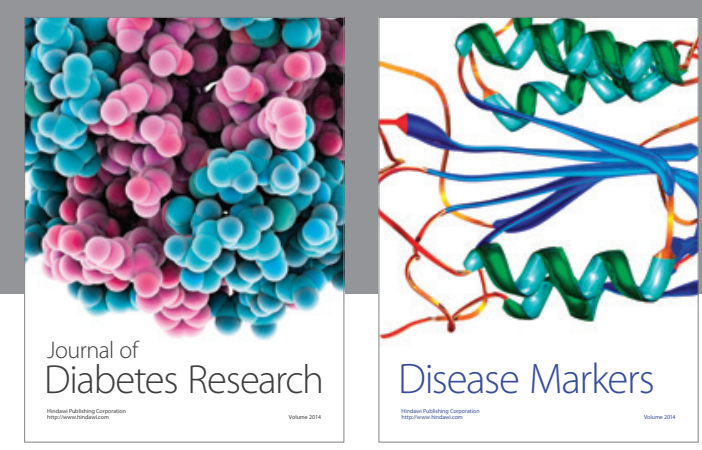

Disease Markers
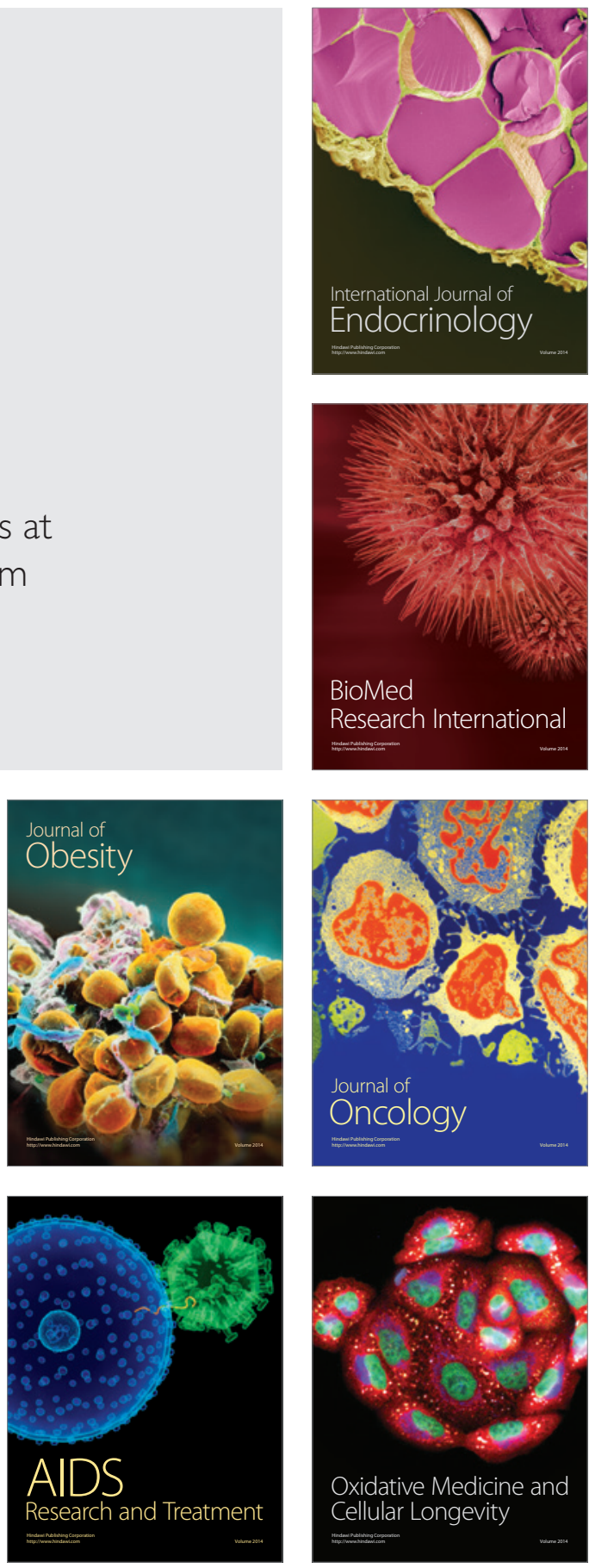